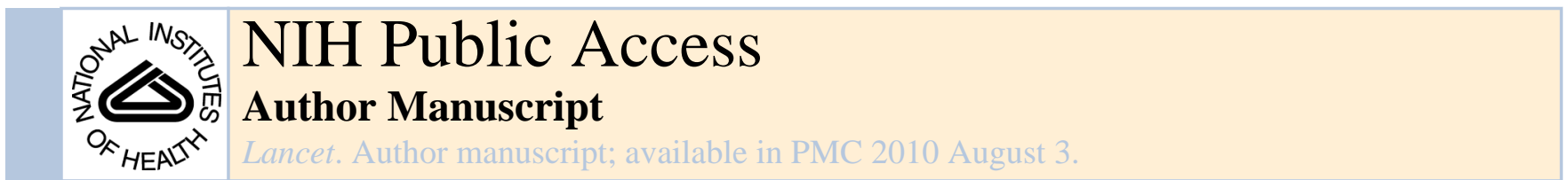

Published in final edited form as:

Lancet. 2009 November 21; 374(9703): 1754-1764. doi:10.1016/S0140-6736(09)61492-6.

Address Correspondence to: Michael E. Wechsler, M.D., Brigham and Women's Hospital, 75 Francis Street, Boston, MA, 02115, USA; phone: 617732 8202, fax: 617732 7421, mwechsler@partners.org.

Address reprint requests to Dr. Chinchilli at the Department of Public Health Sciences, A210, Penn State College of Medicine, 600 Centerview Drive, Suite 2200, Hershey, PA 17033-0855 (vchinchi@ psu.edu).

Acknowledgement of the following contributors:

Linda L. Engle, Kelly Bixler, Aimee J. Merchlinski, Kerrie Sheaffer, Ronald R. Zimmerman Jr., Penn State College of Medicine; Sreedhar Bunga, Gautham Marigowda, Brigham and Women's Medical Hospital; Jennifer Brandorff, Mary Gill, Juno Pak, Allen Stevens, National Jewish Medical Research Center;, Barbara A. Miller, Ann Sexton, University of Wisconsin School of Medicine and Public Health; Peggy Cadbury, Jean Schenkkan, University of California, San Francisco Medical Center; Elise Bender, ,Steve DeMartino, Pamela Kemp, Washington University, School of Medicine; Paul Ferguson, University of California, San Diego Medical Center; Bob Hmieleski, Bill Kahn, Jeffrey Krings, Susan Trahan, Cheryl Wilmoth, Wake Forest University, School of Medicine.

Disclosure: Drs. Boushey, Lemanske, Martin, their institutions, and the Brigham \& Women's Hospital are inventors on a patent concerning the use of genotype at the $\beta_{2}$-adrenergic receptor and effects of regular albuterol use.

\title{
Authors and Contributions:
}

Michael E. Wechsler, Susan J. Kunselman, Vernon M Chinchilli, Eugene Bleecker, Homer A. Boushey, William J. Calhoun, William Ameredes, Mario Castro, Timothy J Craig, Loren Denlinger, John Fahy, Nizar Jarjour, Shamsah Kazani, Sophia Kim, Monica Kraft, Stephen C. Lazarus, Robert F Lemanske, Amy Markezich, Richard J. Martin, Perdita Permaul, Stephen P Peters, Joe Ramsdell, Christine A. Sorkness, E Rand Sutherland, Stanley J Szefler, Michael J Walter, Stephen Wasserman, and Elliot Israel declare that they participated in the design of the study, running of the study, analysis of data, writing of the manuscript, and have seen and approved the final version of the manuscript.

\section{Conflict of Interest:}

Dr. Wechsler reports that he has consulted for or participated in advisory boards or speaker bureaus for AstraZeneca,

GlaxoSmithKline, Schering Plough, Novartis, Genentech, Merck, Medicinova and Sepracor. Ms. Kunselman reports no conflicts. Dr. Chinchilli reports no conflicts. Dr. Bleecker reports serving as a consultant, giving presentations and performing clinical trials which were administered by Wake Forest University Health Sciences for AstraZeneca, GlaxoSmithKline and Novartis. Dr. Boushey reports research project support from GlaxoSmithKline, participating on a scientific advisory committee for GlaxoSmithKline; ad-hoc consulting for Altana, Boehringer-Ingelheim, Genentech, Nanomix, Novartis, Sumitomo, Theravance and Watermark Research; and honoraria for lectures and presentations from Merck, Novartis, Sanofi-Aventis and Genentech. Dr. Calhoun reports no conflicts. Dr. Ameredes reports no conflicts. Dr. Castro reports no conflicts. Dr. Craig reports performing research with Schering, Merck, GlaxoSmithKline, Boehringer-Ingelheim, Altana, Genentech/Novartis, and Forrest; grants for investigator initiated research from Viropharma, CSL Mehring, GlaxoSmithKline and Merck; honorarium for consultative services from Teva, Alcon, Novartis, Genentech, Dyax, CSL Behring, Viropharma, Shire and Pharming; and honorarium for speaking from Teva Schering, Merck, Astra Zeneca, S. Aventis, Genentech and Novartis. Dr. Denlinger reports no conflicts. Dr. Fahy reports providing consulting services for Abgenix, Aerovance, Amira, Biogen, Cytokinetics, Gilead, Merck, Oxagen and Roche. Dr. Jarjour reports receiving advisory board honorarium and clinical trial support from GlaxoSmithKline; consulting fees from Asthmatx; advisory board compensation, lecture honorarium and clinical trial support from Genentech-Novartis; trial support from MedImmune; and clinical trial support and lecture honorarium from Merck. Dr. Kazani reports no conflicts. Dr. Kim reports no conflicts. Dr. Kraft reports speaker's bureau for GlaxoSmithKline; advisory board/consultantion for GlaxoSmithKline, Merck, Novartis and Amira; and research funding from GlaxoSmithKline, Bronchus, GE Healthcare, Asthmatx, Novartis and Genentech. Dr. Lazarus reports no conflicts. Dr Lemanske reports receiving speaker honorarium from Merck, Astra Zeneca, Medicus Group, Park Nicolet Institute; consultant honorarium from Astra Zeneca, MAP Pharmaceuticals, Gray Consulting, Smith Research, Merck Childhood Asthma Network, Novartis, Quintiles/ ANOVAs and Rchorowitz \& Co.; and serving as an author of Up-to-Date. Dr. Markezich reports no conflicts. Dr. Martin reports conflicts with GlaxoSmithKline, Merck, Genentech, Novartis, Altana and Teva. Dr. Permaul reports no conflicts. Dr. Peters reports pharmaceutical trial support as a member of the Wake forest University Clinical Trials Group sponsored by Abaris, Amgen, Altana, Boehringer-Ingelheim, Contocor, Genentech, GlaxoSmithKline, Medimmune, Novartis, Pfizer, Schering and Wyeth; consulting under the auspices of Adelphi, Exocrine, AstraZeneca, Bristol-Meyers Squibb, Ception Therapeutics, Dey, Dyson, Genentech, Johnson \& Johnson, Merck, Novartis, RAD Foundation, Respiratory Medicine, Respiratory Research, Sepracor and Teva; and participating in Physician Education Programs sponsored by AdvanceMed, AstraZeneca, Creative Educational Concepts, DIME, Merck Pharmaceuticals, Genentech, Novartis, Practicome, Pri-Med/SCIOS, Respiratory and Allergic Disease (RAD) Foundation, and UpToDate. Dr. Ramsdell reports no conflicts. Dr. Sorkness reports receiving honorarium for Speaker's bureau and consultation from GlaxoSmithKline; and receiving research support from Pharmaxis and Schering. Dr. Sutherland reports serving as an advisor or consultant to Dey, GlaxoSmithKline and Schering-Plough; and receiving grant funding from Boehringer-Ingelheim, Dey, GlaxoSmithKline, and Novartis. Dr. Szefler reports serving as a consultant for GlaxoSmithKline, Genentech and Merck; and research funding from Ross and GlaxoSmithKline. Dr. Walter reports no conflicts. Dr. Wasserman reports grant support from Merck and Schering-Plough; and serving as a consultant for Amylin. Dr. Israel reports participating in a funded clinical research trial and serving as a consultant with GlaxoSmithKline; participating in a funded clinical research trial with Boehringer Ingelheim; participating in a funded clinical research trial, serving as a consultant, and receiving Speaker's fees from Novarits; and attending a Speaker's symposium and serving as a consultant for AstraZeneca. 


\title{
Effect of $\beta_{2}$-adrenergic receptor polymorphism on response to longacting $\beta_{2}$ agonist in asthma (LARGE trial): a genotype- stratified, randomised, placebo-controlled, crossover trial
}

\author{
Michael E. Wechsler, Susan J. Kunselman, Vernon M Chinchilli, Eugene Bleecker, Homer \\ A. Boushey, William J. Calhoun, Bill T. Ameredes, Mario Castro, Timothy J Craig, Loren \\ Denlinger, John V. Fahy, Nizar Jarjour, Shamsah Kazani, Sophia Kim, Monica Kraft, \\ Stephen C. Lazarus, Robert F Lemanske Jr, Amy Markezich, Richard J. Martin, Perdita \\ Permaul, Stephen P Peters, Joe Ramsdell, Christine A. Sorkness, E Rand Sutherland, \\ Stanley J Szefler, Michael J Walter, Stephen Wasserman, and Elliot Israel for The National \\ Heart, Lung, And Blood Institute's Asthma Clinical Research Network
}

\section{Summary}

Background-Combined long-acting $\beta_{2}$-agonist and inhaled corticosteroid (LABA/ICS) therapy improves outcomes in many asthmatics. Some studies suggest that patients homozygous for arginine at the $16^{\text {th }}$ amino-acid position of the $\beta_{2}$ adrenergic receptor (B16 Arg/Arg) benefit less than those with B16 Gly/Gly.

\begin{abstract}
Methods-In an NIH-funded, B16 genotype-stratified, prospective, randomized, double-blind, placebo-controlled, cross-over trial (www.ClinicalTrials.gov registration ID NCT00200967), we compared adding salmeterol or placebo to ICS in patients with moderate asthma, using AM PEF as the primary outcome.
\end{abstract}

\begin{abstract}
Findings-After 18 weeks, $\operatorname{Arg} / \operatorname{Arg}(n=42)$ and Gly/Gly ( $n=45)$ subjects had greater AM PEF with salmeterol than placebo, with no difference in improvement by genotype (Arg/Arg 21.4 ( $\mathrm{p}<0.0001)$ vs. Gly/Gly $21.5 \mathrm{~L} / \mathrm{min}(\mathrm{p}<0.0001) ; 0.1 \mathrm{~L} / \mathrm{min}$ difference between genotypes, $95 \%$ CI $(-14.2,14.4), \mathrm{p}=0.99)$. In Gly/Gly subjects, methacholine $\mathrm{PC}_{20}$ (a secondary outcome) doubled when salmeterol was added to ICS ( $\mathrm{p}<0.0001$ ), but remained unchanged in Arg/Arg subjects $(\mathrm{p}=0.87)$ (1.32 doubling dose difference between genotypes (95\%CI 0.43,2.21), $\mathrm{p}=0.0038)$. An exploratory posthoc subset analysis of African Americans showed that salmeterol improved the AM and PM PEF for the 8 Gly/Gly subjects $(29 \mathrm{~L} / \mathrm{min}, \mathrm{p}=0.013$ and $45 \mathrm{~L} / \mathrm{min}, \mathrm{p}=0.0005$, respectively) but not for the $9 \mathrm{Arg} / \mathrm{Arg}$ subjects $(-12 \mathrm{~L} / \mathrm{min}, \mathrm{p}=0.57$ and $-2.2 \mathrm{~L} / \mathrm{min}, \mathrm{p}=0.92$, respectively).
\end{abstract}

Interpretation-B16 Arg/Arg and Gly/Gly patients experience improved airway function with salmeterol added to moderate-dose ICS. While these data provide reassurance that in the general population these polymorphisms should not alter the use of LABA with moderate-dose ICS, the significance of the genotype-differentiated response in airway reactivity favoring Gly/Gly subjects and the post-hoc analysis in African Americans require further investigation.

\section{Keywords}

Asthma; pharmacogenetics; beta-adrenergic receptor; beta-agonists; salmeterol

\section{Introduction}

Combination therapy with a long-acting $\beta_{2}$-agonist (LABA) and an inhaled corticosteroid (ICS) is among the most widely prescribed asthma controller medications in the world. Some studies suggest that this combination (LABA/ICS), on average, improves lung 
function and asthma control (1); others suggest that a subpopulation of asthmatics may be at risk for severe exacerbations or death with use of LABAs $(2,3)$.

$B_{2}$-agonists act primarily at the $\beta_{2}$-adrenergic receptor (ADRB2). A common single nucleotide polymorphism (SNP) in the coding region of ADRB2 codes for arginine instead of glycine at the $16^{\text {th }}$ amino-acid of the receptor (allele frequency 0.4 in Caucasians). In retrospective and prospective studies, in patients not taking ICS, regular use of short-acting $\beta_{2}$-agonists (SABAs) such as albuterol was associated with lower lung function in individuals homozygous for arginine at the $16^{\text {th }}$ amino-acid position (B16 Arg/Arg) than in individuals homozygous for glycine at that position (B16 Gly/Gly) $(4,5)$. Another study demonstrated increased risk of exacerbations with regular use of albuterol but not salmeterol in B16 Arg/Arg patients(6).

Given these genotype-specific findings, we performed a genotype-stratified retrospective analysis of patients who had participated in randomized trials using the LABA salmeterol (7). B16 Arg/Arg was associated with a lack of benefit with LABA use, even when the LABA was used with a concomitant ICS(7). We therefore examined prospectively whether these polymorphisms differentially affected outcomes in response to LABA use in a trial comparing the effects of salmeterol with an ICS versus ICS alone in B16 Arg/Arg patients with asthma versus B16 Gly/Gly patients with asthma.

\section{Methods}

The study schema is depicted in Figure 1 and described below.

\section{Screening}

Subjects were recruited from the clinical practices of each site and through community advertising using a variety of media. After subjects gave informed consent (approved by participating site institutional review boards), medical history was reviewed (e.g., medication use and asthma exacerbation history), participants were screened for eligibility based on inclusion and exclusion criteria (Table 1), and blood was obtained. B16 genotyping by restriction fragment length polymorphism was confirmed by sequencing (see on-line repository for genotyping details).

\section{Pre-Matching/Matching}

Arg/Arg or Gly/Gly individuals who met study criteria entered a pool of eligible patients waiting to be matched against their opposite genotype, stratified by $\mathrm{FEV}_{1}$ and race (Caucasian vs. non-Caucasian). Arg/Gly subjects were excluded because they demonstrated inconsistent findings in prior studies and because preliminary data with both SABA and LABA was based on Arg/Arg-Gly/Gly differences. Match-eligible participants began treatment with open-label ICS, beclomethasone HFA (QVAR, TEVA, Israel) $240 \mathrm{mcg}$ BID and PRN albuterol, and returned after 3 weeks of treatment for spirometry to establish baseline $\mathrm{FEV}_{1}$ for matching with individuals of the alternate genotype. Participants returned every 4 weeks thereafter for diary review, medication compliance review, spirometry, and safety checks until a match was identified. Matched participants (an Arg/Arg and a Gly/Gly subject within $10 \%$ of percent predicted $\mathrm{FEV}_{1}$ and of the same race (Caucasian vs. nonCaucasian)) returned to enter the main study.

\section{8-Week Run-In Period}

In order to wash out from prior LABA use (that in prior studies was observed to last as long as 8 weeks (7)), matched subjects entered an 8-week run-in period to establish baseline parameters, continuing treatment with open-label beclomethasone HFA $240 \mathrm{mcg}$ BID and 
using inhaled albuterol as a "rescue therapy." Asthma control was monitored by peak expiratory flow (PEF) via an electronic peak flow meter (EPFM) (AM1 device, Cardinal Health, Yorba Linda, CA), spirometric values, AM/PM peak flow variability index, asthma symptoms, quality of life(8), use of rescue therapy, and events of adverse asthma control(9). Baseline data were collected regarding airway responsiveness (methacholine $\mathrm{PC}_{20}$ ), bronchodilator response to ipratropium, bronchodilator response to albuterol, exhaled nitric oxide, and $\mathrm{pH}$ in exhaled breath condensates $(\mathrm{EBC} \mathrm{pH})$.

\section{8-Week Double-Blind Treatment Period 1}

Subjects were randomized to an 18-week double-blind treatment phase, receiving open-label regularly scheduled inhaled beclomethasone HFA $240 \mathrm{mcg}$ BID and either inhaled LABA (salmeterol 50 mcg BID (Serevent 50 mcg diskus, GSK, North Carolina)) or matching placebo. Randomization was performed via a password-protected, web-based scheme administered by the ACRN Data Coordinating Center whereby individuals in a matched pair were randomized to the same treatment sequence. Each subject was assigned a drug kit number from which his/her blinded medications were dispensed for the duration of the study. Details regarding the assigned treatment order were concealed from participants, clinical staff, and statisticians during study implementation and analysis. Asthma control was monitored by the above indicators, and ipratropium (Atrovent, Boehringer Ingelheim, CT) was used as the primary rescue therapy, 2 puffs PRN.

\section{8-Week Run-Out Period}

After the blinded treatment period, subjects returned to regular-use open-label ICS (beclomethasone HFA 240 mcg BID) with PRN albuterol for an 8-week run-out period, which also served as the run-in period for the second stage of the study.

\section{8-Week Double-Blind Treatment Period 2}

At the end of the first run-out period, subjects were crossed over to the alternate doubleblinded treatment regimen with either a LABA or placebo. Asthma control was monitored by the same indicators as in the first stage. Ipratropium was again used as the primary rescue therapy.

\section{0-Week Study Run-Out}

After the second blinded treatment period, subjects returned to regular-use open-label ICS with PRN albuterol for a 10 -week run-out period ${ }^{1}$; asthma control was monitored by the same indicators as in the first run-out period.

During the two treatment periods, participants used inhaled ipratropium bromide as primary rescue therapy to avoid the confounding effects of $\beta_{2}$-adrenergic stimulation on outcome variables. However, if an episode of adverse asthma control responded incompletely to ipratropium, albuterol was used as a superseding rescue therapy.

\section{Adherence and Monitoring}

Subject adherence with medication dosing was determined with a DOSER ${ }^{\mathrm{TM}}$ device (Meditrack Products; Hudson, MA), which registers each actuation of the metered-dose inhaler (MDI) and stores a daily history, attached to each beclomethasone MDI and reviewed at each clinic visit; and salmeterol Diskus inhalation counters to determine the

\footnotetext{
${ }^{1}$ While the second run-out period was 10 weeks (as opposed to 8 weeks in the first run-out period) to assess whether any potential genotype-specific effects would be observed out to 10 weeks, run-out measurements were taken at the end of 8 weeks and compared with the end of the first 8 week run-out period.
} 
number of inhalations used. These two devices gave objective measurements of the number of puffs/doses actuated.

Subjects' diary cards recording number of puffs of each medication/day were used as a secondary source of compliance information. This information was compared with PEF measurements electronically recorded and date/time stamped from the EPFM device. Because subjects were instructed to perform their morning and evening PEF maneuvers immediately before taking their study medications, timing of PEF monitoring was used as a surrogate for timing of dosing with study medications.

\section{Outcome Variables}

This study's primary question, assessed separately within and between genotypes (B16-Arg/ Arg, B16-Gly/Gly), was whether the treatment regimens differ with respect to AM PEF at the end of 18-week treatment. Secondary response variables examined include other physiologic variables and biomarkers of inflammation, as well as asthma quality of life (AQLQ)(8). These included: PM PEF, peak flow variability ([PM PEF - AM PEF]/PM $\mathrm{PEF}$ ), $\mathrm{FEV}_{1}$, airway responsiveness (methacholine $\mathrm{PC}_{20}$ ), reversibility with 4 puffs of either ipratropium or albuterol, exhaled nitric oxide, and $\mathrm{EBC} \mathrm{pH}$, as previously described (10). Genotype-specific outcomes were also examined after stratification by gender and race The asthma control variables analyzed include averaged daily symptom scores (measured on a scale from 0 (absent) to 3 (severe)), number of actuations of rescue MDI (ipratropium, albuterol, and the combined total during treatment periods), number of exacerbations, episodes of adverse asthma control, and asthma-related quality of life. Variables measured daily from the subject diary cards, e.g., PEF, PEF variability, symptoms, and rescue therapy use, were averaged between visits and weighted by the inverse of the squared standard error. The purpose of the weighting scheme for diary card data was to assign greater weight to means measured with low variability and less weight to means measured with high variability.

\section{Statistical Analysis}

Means (standard deviations) were calculated as descriptive statistics for baseline variables, except for those variables with skewed distributions in which medians or geometric means (first (Q1) and third quartiles (Q3)) were calculated. Paired t tests, Wilcoxon signed rank tests, and McNemar tests were applied, corresponding to type of descriptive statistics, to compare genotypic groups with respect to baseline variables while accounting for matched pairs. Because of repeated measurements of primary and secondary response variables over time, the statistical analysis employed was longitudinal data analysis, incorporating all data from study participants. For the primary outcome variable (AM PEF) and several of the secondary outcomes, we invoked a mixed-effects linear model (11-13) that included an intercept and three slopes for the first treatment period (study weeks 8-10, weeks 10-14, and weeks 14-26) and an intercept and three slopes for the second treatment period (study weeks 34-36, weeks 36-40, and weeks 40-52). Because we were primarily interested in the genotype stratified response to therapy while on LABA vs. placebo following 18 weeks of therapy, run-in and run-out data were not included because therapy was altered significantly when subjects went from run-in to treatment (ICS $\rightarrow$ LABA/ICS or ICS $\rightarrow$ placebo/ICS) and from treatment to run-out period (LABA/ICS or placebo/ICS $\rightarrow$ ICS). Inclusion of either of these phases could artificially alter the longitudinal model, and not reflect true treatment related effects. Model parameters were estimated separately for each genotype and randomized drug sequence (i.e., Placebo/ICS followed by LABA/ICS or LABA/ICS followed by Placebo/ICS). Outcome variables based on daily diary records were averaged over all of the days between clinic visits prior to data analysis. For most outcome variables, 
values were estimated from the model for the beginning and end of each treatment period, and appropriate contrasts comparing treatment regimens (LABA/ICS versus Placebo/ICS) were calculated. Run-out data were modeled separately fitting an intercept and one slope for the first run-out (study weeks 26-34) and an intercept and one slope for the second run-out (study weeks 52-62). Different model specifications were required for secondary outcome variables that were not collected at all study visits (e.g., methacholine $\mathrm{PC}_{20}$ was collected only at the beginning and end of each treatment period, allowing for estimation of only one treatment period slope). Rescue use and symptom score data exhibited scant variability, and values were generally very small (close to 0 ). Therefore, these outcome variables were analyzed via Wilcoxon signed rank tests and Wilcoxon rank sum tests. Hodges-Lehmann estimates for the median paired difference (within genotype) and median difference (between genotypes) with 95\% confidence intervals are presented(14). See the on-line repository for more detailed explanations of these statistical analyses.

PROC MIXED of the SAS/STAT ${ }^{\circledR}$ statistical analysis software version 9.1 (SAS Institute Inc., Cary, NC) was used for all of longitudinal data analyses, with other SAS procedures for additional statistical analyses. S-plus ${ }^{\circledR}$ (Insightful Corporation, Seattle, WA) was used to generate high-level graphics. P-values < 0.05 were considered statistically significant; no adjustment was made for analysis of multiple secondary outcomes.

As part of an "intention-to-treat" analysis, all available data on randomized patients were included in the statistical analysis, regardless of whether a patient had missed some visits, dropped out, or been non-compliant. An exception was made for three B16 Arg/Gly subjects who were incorrectly categorized as Gly/Gly subjects and initially randomized in the trial. Data for these three subjects were removed from all reported analyses (action approved by the Data and Safety Monitoring Board). Of note, investigators performing the data analyses were blinded to both genotype and treatment allocation.

\section{Sample Size}

With the standard deviation of the primary contrast of interest (i.e., comparing the estimate at the end of the placebo/ICS treatment period with the estimate at the end of the LABA/ICS treatment period) with respect to AM PEF from the ACRN BARGE trial ( $24 \mathrm{~L} / \mathrm{min})$, a sample size of 24 subjects per genotype was required to detect a difference of $25 \mathrm{~L} / \mathrm{min}$ between Arg/Arg and Gly/Gly with a two-sided, 0.05 significance level test with 90\% statistical power and accounting for a $15 \%$ drop-out rate. However, to attain $90 \%$ statistical power for the secondary outcome variable of $\mathrm{FEV}_{1}$, a sample size of 40 subjects per genotype (80 total randomized subjects) was required for an effect size of $0.15 \mathrm{~L}$ with an estimated standard deviation of $0.19 \mathrm{~L}$. With a sample size of 40 subjects per genotype, the actual effect size for detecting between-genotype differences with respect to end-oftreatment AM PEF was $15 \mathrm{~L} / \mathrm{min}$, and the effect sizes for detecting treatment regimen differences within each genotype are 13.3 L/min for AM PEF and $0.13 \mathrm{~L}$ for $\mathrm{FEV}_{1}$.

\section{Role of the funding sources}

The study was funded by the National Heart, Lung and Blood Institute (NHLBI) of the US National Institutes of Health. An NHLBI-appointed protocol review committee approved the study design and reviewed the final manuscript but played no other role in the study. Openlabel ipratropium bromide was provided by Boehringer Ingelheim Pharmaceuticals, Inc., and open-label beclomethasone HFA was provided by Teva Pharmaceuticals Industry, Ltd. Neither company had input into trial design; data collection, analysis, management, or interpretation; writing of the report; nor in the decision to submit the paper for publication. 


\section{Results}

474 patients were screened for the trial between 2004 and 2006. The B16 alleles were in Hardy-Weinberg equilibrium ( $\mathrm{p}=0.95)$ in this population. 244 subjects had eligible genotypes (78 B16 Arg/Arg and 166 B16 Gly/Gly). Several of these subjects (9 Arg/Arg and 42 Gly/Gly) withdrew consent following screening because no appropriate match was identified and they no longer wanted to participate in the pre-match protocol. Forty-two B16 Arg/Arg and 45 B16 Gly/Gly subjects were randomized (Figure 2).

Demographic, clinical, and physiological characteristics of randomized subjects at enrollment in the run-in of the main study (following at least 3 weeks of standard inhaled corticosteroid therapy) are in Table 2. Matching by lung function was successful. Mean $\mathrm{FEV}_{1}$ was $78.6 \%$ predicted in Arg/Arg subjects and $79.6 \%$ predicted in Gly/Gly subjects. At baseline, patients in both genotypic groups used an average 1 puff/day of rescue albuterol. Arg/Arg and Gly/Gly subjects did not differ significantly at the beginning of each treatment period with respect to any measured baseline characteristic (data not shown).

Of 1910 scheduled main study visits, 1901 (99.5\%) were completed. During the doubleblind treatment periods, subjects recorded their AM PEF 95.7\% (90.1\%, 98.4\%) (median $(\mathrm{Q} 1, \mathrm{Q} 3))$ of the days. Based on data from the DOSER ${ }^{\mathrm{TM}}$ and the Diskus, subjects took $95.1 \%(90.1 \%, 97.9 \%)$ of their scheduled QVAR puffs and $94.9 \%(88.2 \%, 98.6 \%)$ of their scheduled LABA/placebo puffs.

After 18 weeks, LABA/ICS treatment resulted in an AM PEF 21.4 (95\% CI $(11.8,31.1)) \mathrm{L} /$ min greater than treatment with placebo/ICS in Arg/Arg subjects ( $\mathrm{p}<0.0001)$. Similarly, in Gly/Gly subjects, AM PEF following treatment with LABA/ICS was 21.5 (95\% CI (11.0, 32.1)) $\mathrm{L} / \mathrm{min}$ greater than treatment with placebo/ICS ( $<<0.0001)$. The difference between genotypes (Arg/Arg - Gly/Gly) was $-0.1(95 \%$ CI $(-14.4,14.2)$ ) L/min ( $\mathrm{p}=0.99)$ (Figure $3 a)$. Figure $3 \mathrm{~b}$ reveals both the raw and modeled data for AM PEF in B16 Arg/Arg and Gly/ Gly subjects receiving ICS with placebo or LABA from beginning to end of the 18 week treatment periods. There was no significant difference between the two genotype groups $(\mathrm{p}=0.99)$. Correspondingly, AM PEF in the run-out did not differ significantly between those treated with LABA/ICS or placebo/ICS (data not shown)

Analyses of prespecified secondary outcomes are shown in Table 3. This table includes results of outcome characteristics stratified by genotype and between different treatment options following 18 weeks of each treatment regimen. The difference between genotypes for each treatment option is also reported (Arg/Arg difference- Gly/Gly difference). There were within- genotype differences between the LABA/ICS and placebo/ICS groups with respect to PM PEF, peak flow variability, $\mathrm{FEV}_{1}, \mathrm{FEV}_{1}$ reversibility with albuterol, asthma symptoms, rescue therapy use, and methacholine $\mathrm{PC}_{20}$. Most changes were quite small, and there were no other genotype specific differences (Arg/Arg vs. Gly/Gly), except for methacholine $\mathrm{PC}_{20}$. In Gly/Gly subjects, the methacholine $\mathrm{PC}_{20}$ doubled when LABA was added to ICS ( $\mathrm{p}<0.0001)$, while in Arg/Arg subjects it remained unchanged ( $\mathrm{p}=0.87)$ (Figure 4a). The genotype-specific difference in methacholine responsiveness was significant (1.32 doubling dose difference between genotypes $(95 \% \mathrm{CI} 0.43,2.21) \mathrm{p}=0.0038)$ and plots of individual subjects are depicted in Figure $4 \mathrm{~b}$ (and in online supplement). Of note, there were no significant differences in exhaled NO nor in $\mathrm{EBC} \mathrm{pH}$.

Both genotype groups had a relatively high degree of reversibility to 4 puffs of ipratropium (7.6-10.1\%), comparable to the degree of reversibility following 4 puffs of albuterol (6.7$10.8 \%$ ) (Table 3). Post-bronchodilator $\mathrm{FEV}_{1}$ was comparable when participants took albuterol or ipratropium. There was no genotype-specific advantage for one bronchodilator over another. However, independent of genotype, the degree of bronchodilation with 
albuterol was significantly higher when subjects were on placebo/ICS than on LABA/ICS ( $10.3 \%$ vs. $6.7 \%$ in $\mathrm{Arg} / \mathrm{Arg}, \mathrm{p}=0.001,10.8 \%$ vs. $8.5 \%$ in Gly/Gly, $\mathrm{p}=0.04)$. This finding was not observed with ipratropium; individuals responded equally to ipratropium whether taking placebo/ICS or LABA/ICS.

As expected, exacerbation rates were low (7 Arg/Arg subjects, 5 with placebo/ICS and 2 with LABA/ICS, versus 6 Gly/Gly subjects, 3 with placebo/ICS and 3 with LABA/ICS), and no genotype-specific differences were appreciated. Five serious adverse events were reported, one each during the pre-match and run-in phases on open-label ICS, two during double-blind treatment with LABA/ICS, and one during double-blind treatment with Placebo/ICS. None of the serious events was asthma-related or related to study medications or procedures. All subjects recovered. The most prevalent non-serious adverse events reported were expected and respiratory in nature, with 94 events occurring during the prematch/run-in/run-out phases of the study, 74 occurring during double-blind treatment with Placebo/ICS and 57 occurring during double-blind treatment with LABA/ICS. Acute nasopharyngitis and acute pharyngitis comprised the majority of these adverse events.

While results among Caucasian participants alone mirrored those of the entire study population, exploratory post-hoc subgroup analyses in African Americans revealed significant changes in AM and PM PEF in the 8 Gly/Gly subjects $(29 \mathrm{~L} / \mathrm{min}, \mathrm{p}=0.013$ and $45 \mathrm{~L} / \mathrm{min}, \mathrm{p}=0.0005$, respectively) treated with LABA/ICS vs. placebo/ICS but not in the 9 Arg/Arg subjects $(-12 \mathrm{~L} / \mathrm{min}, \mathrm{p}=0.57,-2.2$. L/min, $\mathrm{p}=0.92)$ (Figure 5). PEF measured at clinic visits during spirometry also improved with LABA vs. placebo in African American Gly/Gly (39 L/min, $\mathrm{p}=0.0016)$ but not Arg/Arg subjects ( $-4.8 \mathrm{~L} / \mathrm{min}, \mathrm{p}=0.73)$. Although these subgroups were small, these genotype-specific differences in AM PEF $(p=0.09)$ and PM PEF ( $\mathrm{p}=0.07$ ) approached statistical significance, while clinic-measured PEF reached statistical significance $(\mathrm{p}=0.02)$. Methacholine $\mathrm{PC}_{20}$ differences paralleled the genotypedifferentiated trend in the entire study cohort.

In addition to the African American subjects reported above, there were only 2 Asian Arg/ Arg (only 1 of whom completed a phase of the trial), and 1 Asian Gly/Gly in the dataset, and 4 Hispanic Arg/Arg and 5 Hispanic Gly/Gly. For such small groups, model-derived estimates could not be obtained in our statistical model. Because of the relative heterogeneity of this "other group", it is more appropriate to assess genotype specific differences within ethnic groups if sufficient numbers of subjects are available for analysis.

There were no other significant genotype-specific differences in other subgroups analyzed, including in preplanned subanalyses of those who reversed by greater than or less than $12 \%$ with albuterol, or in posthoc subanalyses including only those who completed the entire trial, those who were on a controller within 6 weeks of study initiation, or males versus females (data not shown).

\section{Discussion}

Over the last decade, several studies have investigated the impact of specific mutations of the beta adrenergic receptor gene on response to $\beta_{2}$-agonists $(5,6)$. The current trial followed our retrospective analysis of ACRN trials that suggested a lack of benefit of LABAs in B16 Arg/Arg individuals, with and without ICS (7).

Despite our retrospective analysis suggesting an ADRB2 Arg16Gly genotype-specific effect on AM PEF with LABA/ICS, we found no such effect in the present study. The addition of LABA to ICS for 18 weeks produced similar improvements in airway caliber as indicated by AM PEF (our primary outcome variable) in both genotype groups. Importantly, there was no decline in PEF during the run-out period as had been observed in trials with SABA $(5,15)$. 
These findings are reassuring and complement other retrospective studies that generally failed to reveal a B16-specific difference in PEF and symptoms with LABA/ICS use $(16,17)$.

A genotype-specific effect was noted in one of our prespecified secondary outcome variables-- methacholine $\mathrm{PC}_{20}$. The discrepant effects of LABA on airway caliber vs. airway reactivity have been previously noted (18). Further, B16 Arg has been associated with greater decreases in bronchoprotection in response to regular use of a LABA than B16 Gly (19). In all these cases, the bronchoprotective effect of LABA was assessed at 12 hours or less after administration. Somewhat surprisingly, in our study, we observed that LABA, when added to ICS, enhanced bronchoprotection occurring in B16 Gly/Gly subjects (doubling dose shift in methacholine reactivity) but not in B16 Arg/Arg subjects ( $\mathrm{p}=0.0038$ for difference between genotypes). This effect was unlikely to be due to persistent bronchodilating effects of LABA, since the methacholine challenges were done following a 24-hour withhold of blinded LABA or placebo. Some in vitro data suggest that LABA and ICS produce synergistic effects through multiple molecular mechanisms (including facilitating the transcription of antiinflammatory genes and by acting as an 'allosteric' modulator, which may modify the conformation of glucocorticoid-bound GR (and/or the binding of necessary cofactors and coactivators)(20,21). Whether such interactions are influenced by polymorphisms in ADRB2 and whether such a finding translates into increased efficacy of ICS/LABA in Gly/Gly patients are unclear. Another potential explanation for the observed difference relates to the observation that Arg/Arg human airway smooth muscle cells (as compared with Gly/Gly) can produce increased amounts of proinflammatory mediators in response to $\beta_{2}$-agonist stimulation (22), which may counteract the increased antiinflammatory effect of the $\beta_{2}$-agonist-corticosteroid synergy.

In a posthoc subanalysis of the African Americans included in our study (20\% of the cohort), we also noted a genotype-specific difference in our primary outcome, AM PEF (both the average of daily home measurements and, separately, PEF measured at clinic visits) as well as PM PEF. The Arg/Arg group did not benefit when LABA was added to ICS, while the Gly/Gly group did; neither group experienced adverse effects. Since our African American subpopulation was small (9 Arg/Arg, 8 Gly/Gly), this lack of improvement in airway function in Arg/Arg African Americans may be due to alpha error and should be considered exploratory; however, this finding, if confirmed, might have important implications. If African Americans do not experience benefit from LABA added to ICS, they might be less likely to comply with such medications. Further, a recent FDA meta-analysis suggested an increased risk of serious adverse outcomes (combined deaths, intubations, and hospitalizations) with LABA use, especially in African Americans (23). If Arg/Arg African Americans do not experience a clinically meaningful benefit from the addition of LABA to ICS, one would most likely consider genotyping and not treating that population with a LABA in the context of a possible increase in serious adverse outcomes. Of interest, a recent prospective study in 475 African Americans (24) found no significant difference in the rate of asthma exacerbations when LABA was added to ICS and only a small difference in $\mathrm{FEV}_{1}$ (3.5\% between these African American treatment groups despite the fact that to enter the study all patients needed to demonstrate a $>12 \%$ improvement in $\mathrm{FEV}_{1}$ while on ICS). While there was a significant reduction in nocturnal asthma, there was no difference in symptom scores, symptom-free days, albuterol use, or albuterol-free days between treatment groups in this African American population. It is interesting to speculate whether the Arg/Arg subjects (20\% of African Americans) contributed to the small degree of improvement seen in this study.

Several additional points are worth noting. We used a moderately high dose of ICS in this study (480 mcg of HFA beclomethasone a day). It is unclear whether genotype-specific 
effects become evident at lower doses of ICS commonly used in combination therapy $(16,17)$. Furthermore, it is important to distinguish the lack of effects on airway function in our study with LABA from studies with SABA. Retrospective and prospective studies with SABA show genotype-specific effects on peak flow, medication use, exacerbations, and/or symptoms (4-6), suggesting a differential response between SABA and LABA and/or that ICS possibly prevent the detrimental response with SABA. Lastly, it is important to realize that the Arg/Arg associations may not be causative. These polymorphisms may be in linkage disequilibrium with other polymorphisms that are, in fact, biologically important. Since our study was genotype-stratified, we could not determine whether haplotypic combinations of polymorphisms showed even greater associations than those we detected.

In summary, the LARGE study demonstrated that B16 Arg/Arg and Gly/Gly patients experience similar and significant improvement in airway function when LABA is added to a moderate dose of an ICS. These findings provide reassurance that in the general population these specific polymorphisms should not alter the use of LABA along with moderate doses of ICS. Nevertheless, we did note several genotype-specific differences in response to therapy. Gly/Gly patients' airway responsiveness improved with salmeterol, while Arg/Arg patients' did not. Further, an exploratory post-hoc analysis in African American patients suggested that those individuals possessing the Arg/Arg genotype, in contrast to Gly/Gly, may not experience improvements with salmeterol beyond those achieved with ICS alone. Due to the small sample size, this finding requires further confirmation. Currently, our overall findings do not suggest any need to modify guidelines or recommendations for the use of LABAs when they are used with moderate doses of ICS.

\section{Supplementary Material}

Refer to Web version on PubMed Central for supplementary material.

\section{Acknowledgments}

We would like to acknowledge the National Heart, Lung and Blood Institute (NHLBI) of the US National Institutes of Health that funded the study and its appointed protocol review committee that approved the study design and reviewed the final manuscript. We also acknowledge the donation of medications for this trial: open-label ipratropium bromide was provided by Boehringer Ingelheim Pharmaceuticals, Inc., and open-label beclomethasone HFA was provided by Teva Pharmaceuticals Industry, Ltd.

Funding references: US NIH/NHLBI - K23-HL04285, U10-HL74227, U10-HL74231, U10-HL074204, U10HL74212, U10-HL74073, U10-HL074206, U10-HL074208, U10-HL74225, U10-HL74218

\section{REFERENCES}

1. Pauwels RA, Lofdahl CG, Postma DS, Tattersfield AE, O'Byrne P, Barnes PJ, et al. Effect of inhaled formoterol and budesonide on exacerbations of asthma. Formoterol and Corticosteroids Establishing Therapy (FACET) International Study Group. N Engl J Med 1997 Nov 13;337(20): 1405-1411. [PubMed: 9358137]

2. Castle W, Fuller R, Hall J, Palmer J. Serevent nationwide surveillance study: comparison of salmeterol with salbutamol in asthmatic patients who require regular bronchodilator treatment. Bmj 1993 Apr 17;306(6884):1034-1037. [PubMed: 8098238]

3. Nelson HS, Weiss ST, Bleecker ER, Yancey SW, Dorinsky PM. The Salmeterol Multicenter Asthma Research Trial: a comparison of usual pharmacotherapy for asthma or usual pharmacotherapy plus salmeterol. Chest 2006 Jan;129(1):15-26. [PubMed: 16424409]

4. Israel E, Drazen JM, Liggett SB, Boushey HA, Cherniack RM, Chinchilli VM, et al. The effect of polymorphisms of the beta2-adrenergic receptor on the response to regular use of albuterol in asthma. Am J Respir Crit Care Med 2000;162:75-80. 2000. [PubMed: 10903223] 
5. Israel E, Chinchilli VM, Ford JG, Boushey HA, Cherniack R, Craig TJ, et al. Use of regularly scheduled albuterol treatment in asthma: genotype-stratified, randomised, placebo-controlled crossover trial. Lancet 2004 Oct 23-29;364(9444):1505-1512. [PubMed: 15500895]

6. Taylor DR, Drazen JM, Herbison GP, Yandava CN, Hancox RJ, Town GI. Asthma exacerbations during long term beta-agonist use: influence of beta2 adrenoceptor polymorphism. Thorax 2000;55:762-767. 2000. [PubMed: 10950895]

7. Wechsler ME, Lehman E, Lazarus SC, Lemanske RF Jr, Boushey HA, Deykin A, et al. BetaAdrenergic receptor polymorphisms and response to salmeterol. Am J Respir Crit Care Med 2006 Mar 1;173(5):519-526. [PubMed: 16322642]

8. Juniper EF, Guyatt GH, Ferrie PJ, Griffith LE. Measuring quality of life in asthma. Am Rev Respir Dis 1993;147:832-838. 1993. [PubMed: 8466117]

9. Juniper EF, O'Byrne PM, Guyatt GH, Ferrie PJ, King DR. Development and validation of a questionnaire to measure asthma control. Eur Respir J 1999 Oct;14(4):902-907. [PubMed: 10573240]

10. Vaughan J, Ngamtrakulpanit L, Pajewski TN, Turner R, Nguyen TA, Smith A, et al. Exhaled breath condensate $\mathrm{pH}$ is a robust and reproducible assay of airway acidity. Eur Respir J 2003 Dec; 22(6):889-894. [PubMed: 14680074]

11. Laird NM, Donnelly C, Ware JH. Longitudinal studies with continuous responses. Stat Methods Med Res 1992;1:225-247. 1992. [PubMed: 1341659]

12. Laird NM, Ware JH. Random-effects models for longitudinal data. Biometrics 1982;38:963-974. 1982. [PubMed: 7168798]

13. Vonesh EF, Carter RL. Mixed-effects nonlinear regression for unbalanced repeated measures. Biometrics 1992;48:1-17. 1992. [PubMed: 1581479]

14. Hollander, M.; Wolfe, DA. Nonparametric statistical methods. 2nd ed.. New York: Wiley; 1999.

15. Israel E, Drazen JM, Liggett SB, Boushey HA, Cherniack RM, Chinchilli VM, et al. Effect of polymorphism of the beta(2)-adrenergic receptor on response to regular use of albuterol in asthma. Int Arch Allergy Immunol 2001 Jan-Mar;124(1-3):183-186. [PubMed: 11306963]

16. Bleecker ER, Nelson H, Corren J, Kraft M, Yancey S, Ortega H, et al. Arg16Gly Polymorphism of the [beta]2-adrenergic Receptor Gene Does Not Modulate Clinical Response to Salmeterol in Subjects with Asthma. Journal of Allergy and Clinical Immunology 2008;121(2, Supplement 1) S143-S.

17. Bleecker ER, Postma DS, Lawrance RM, Meyers DA, Ambrose HJ, Goldman M. Effect of ADRB2 polymorphisms on response to longacting beta2-agonist therapy: a pharmacogenetic analysis of two randomised studies. Lancet 2007 Dec 22;370(9605):2118-2125. [PubMed: 18156033]

18. Lipworth B, Tan S, Devlin M, Aiken T, Baker R, Hendrick D. Effects of treatment with formoterol on bronchoprotection against methacholine. Am J Med 1998 May;104(5):431-438. [PubMed: 9626025]

19. Lee DK, Currie GP, Hall IP, Lima JJ, Lipworth BJ. The arginine-16 beta2-adrenoceptor polymorphism predisposes to bronchoprotective subsensitivity in patients treated with formoterol and salmeterol. Br J Clin Pharmacol 2004 Jan;57(1):68-75. [PubMed: 14678342]

20. Giembycz MA, Kaur M, Leigh R, Newton R. A Holy Grail of asthma management: toward understanding how long-acting beta(2)-adrenoceptor agonists enhance the clinical efficacy of inhaled corticosteroids. Br J Pharmacol 2008 Mar;153(6):1090-1104. [PubMed: 18071293]

21. Cockcroft DW, Swystun VA, Bhagat R. Interaction of inhaled beta 2 agonist and inhaled corticosteroid on airway responsiveness to allergen and methacholine. Am J Respir Crit Care Med 1995;152:1485-1489. 1995. [PubMed: 7582281]

22. Shore SA, Drazen JM. Beta-agonists and asthma: too much of a good thing? J Clin Invest 2003 Aug;112(4):495-497. [PubMed: 12925688]

23. FDA. Statistical Briefing Package. Long-Acting Beta-Agonists and Adverse Asthma Events MetaAnalysis. Joint meeting of the Pulmonary-Allergy Drugs Advisory Committee, Drug Safety and Risk Management Advisory Committee, and Pediatric Advisory Committee 2008 November 12, 2008. [cited 2009 January 16]. Available from: http://www.fda.gov/ohrms/dockets/ac/08/briefing/2008-4398b1-01-FDA.pdf 
24. Bailey W, Castro M, Matz J, White M, Dransfield M, Yancey S, et al. Asthma exacerbations in African Americans treated for 1 year with combination fluticasone propionate and salmeterol or fluticasone propionate alone. Curr Med Res Opin 2008 Jun;24(6):1669-1682. [PubMed: 18462564] 


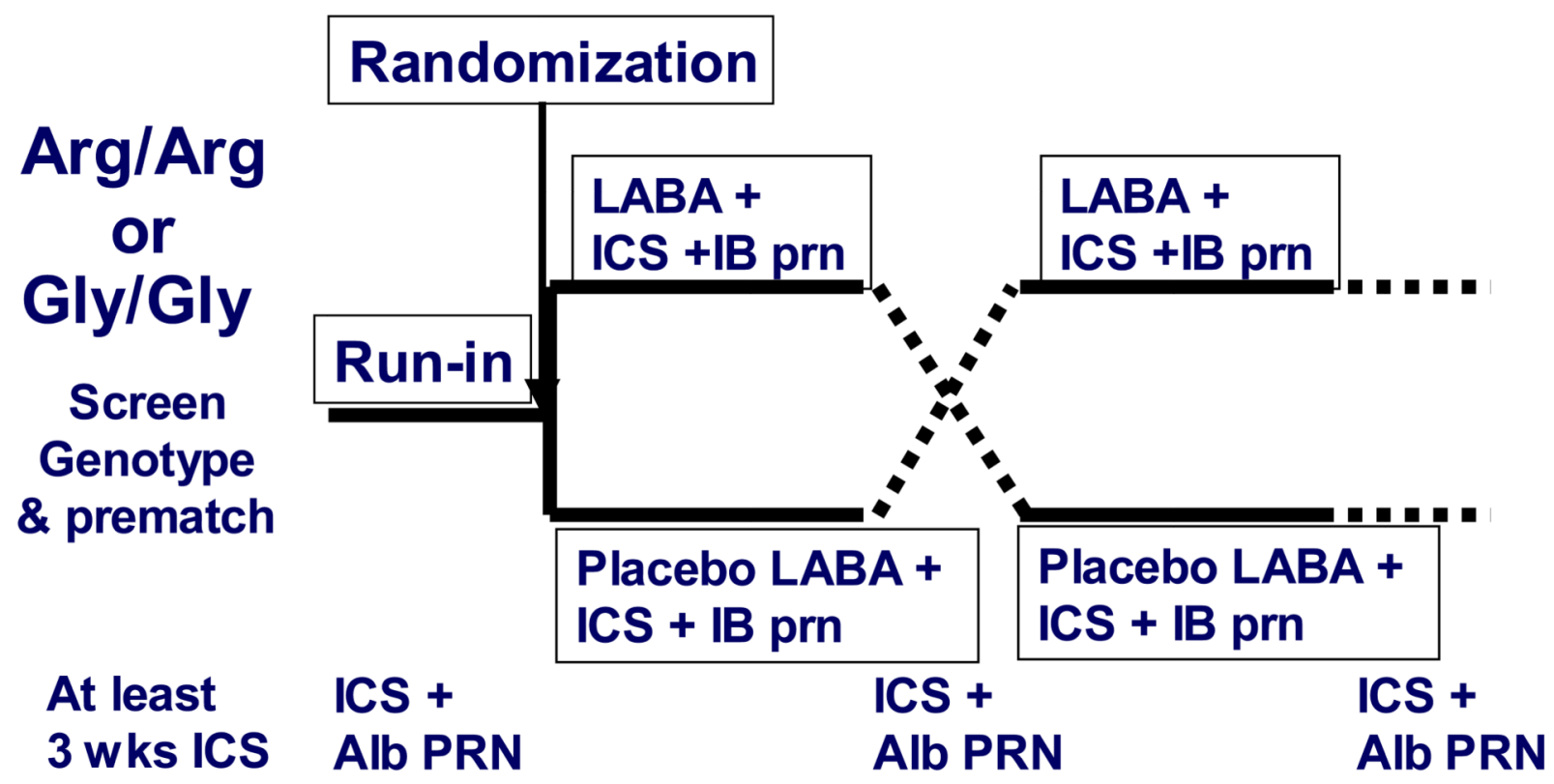

\section{LARGE Trial Design}

Arg/Arg

or

Gly/Gly

Screen

Genotype

\& prematch

$\begin{array}{ll}\text { At least } & \text { ICS + } \\ 3 \text { wks ICS } & \text { Alb PRN }\end{array}$

Alb PRN

Alb PRN

\section{Wks 18Wks 8 Wks 18 Wks 10 Wks}

LABA= LONG ACTING BETAAG; ICS= 240 bid INHALED CORTICOSTEROID; IB - IPRATROPIUM

Figure 1. LARGE study design

Following screening and genotyping, genotype-eligible and matched subjects who received 8 weeks of ICS during the run-in were randomized to continue ICS with either LABA or placebo for 18 weeks, followed by an 8 week runout period on ICS alone, followed by the alternate treatment. 


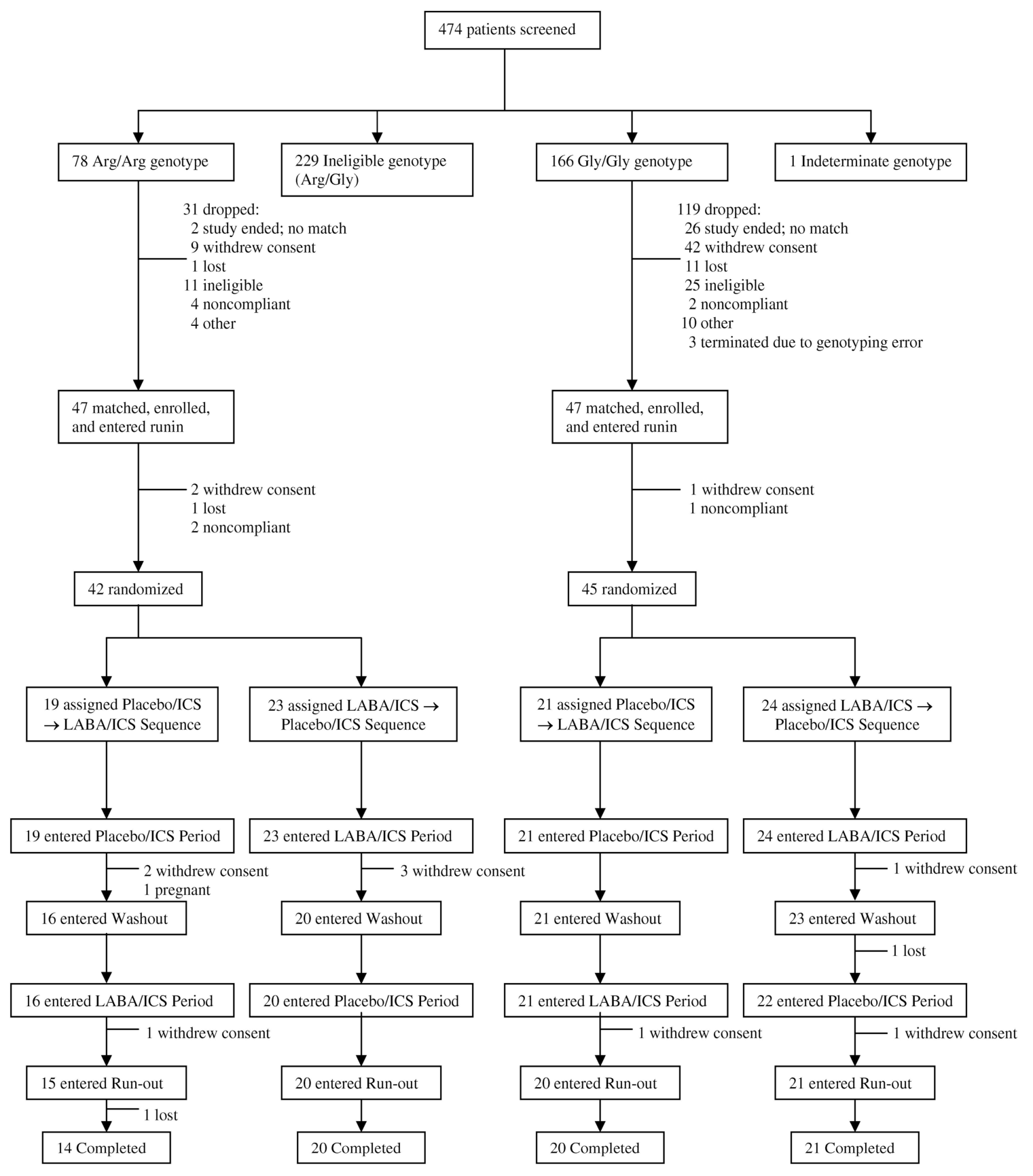

Figure 2. Fate of $\mathbf{4 7 4}$ screened subjects in LARGE trial

42 B16 Arg/Arg individuals and 45 B16 Gly/Gly individuals were randomized to receive 1 of 2 sequential treatment regimens consisting of ICS with either LABA or placebo. 
Figure 3A

\section{AM PEF}

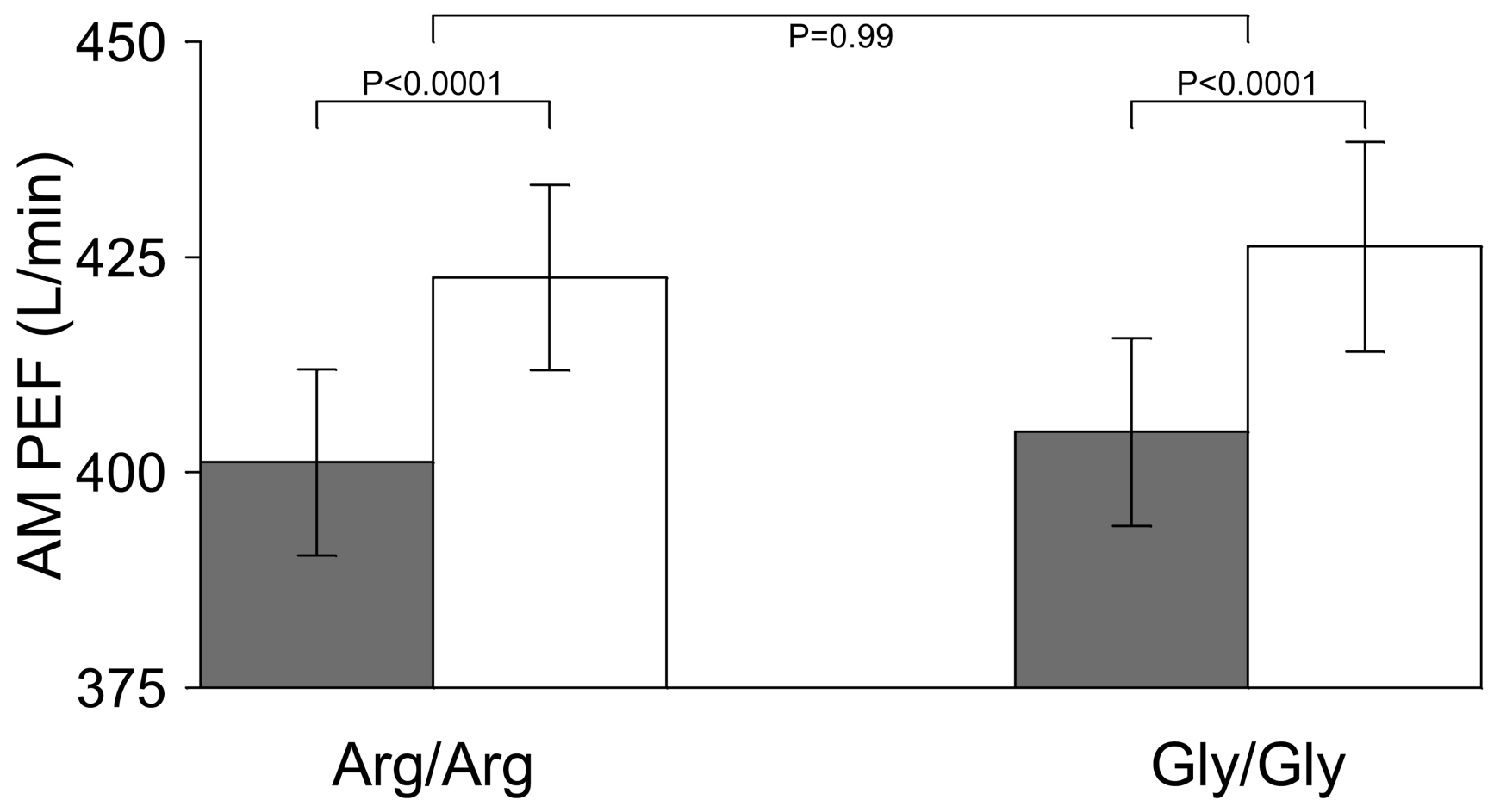

Placebo/ICS

LABA/ICS 
Figure 3B

\section{AM PEF During Treatment}
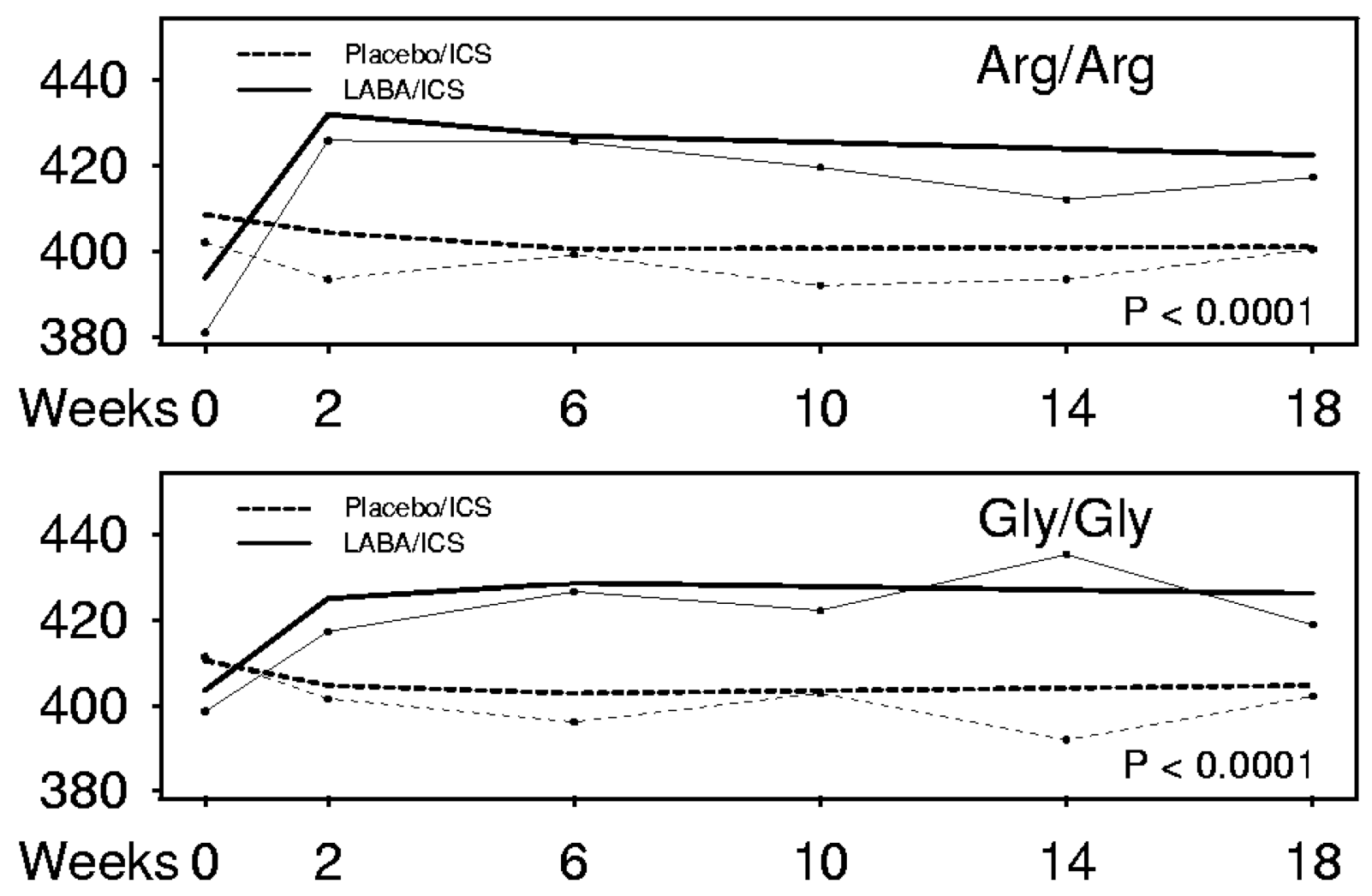

Figure 3.

Figure 3A. AM PEF in B16 Arg/Arg subjects and B16 Gly/Gly subjects receiving ICS with placebo or LABA. Both groups of subjects ended up with a higher AM PEF with LABA/ ICS than with Placebo/ICS, but there was no significant difference between the two groups. Bars represent $95 \%$ confidence limits about the mean.

Figure 3B. AM PEF in B16 Arg/Arg subjects and B16 Gly/Gly subjects receiving ICS with placebo or LABA from beginning to end of 18 week treatment periods (Modeled data= thick lines, Raw data $=$ thin lines). Modeled data account for repeated measurements within subject. P-values are shown for the 18-week comparison within genotype. There was no significant difference between the two genotype groups $(\mathrm{p}=0.99)$. 
Figure 4a

Methacholine $\mathrm{PC}_{20}$

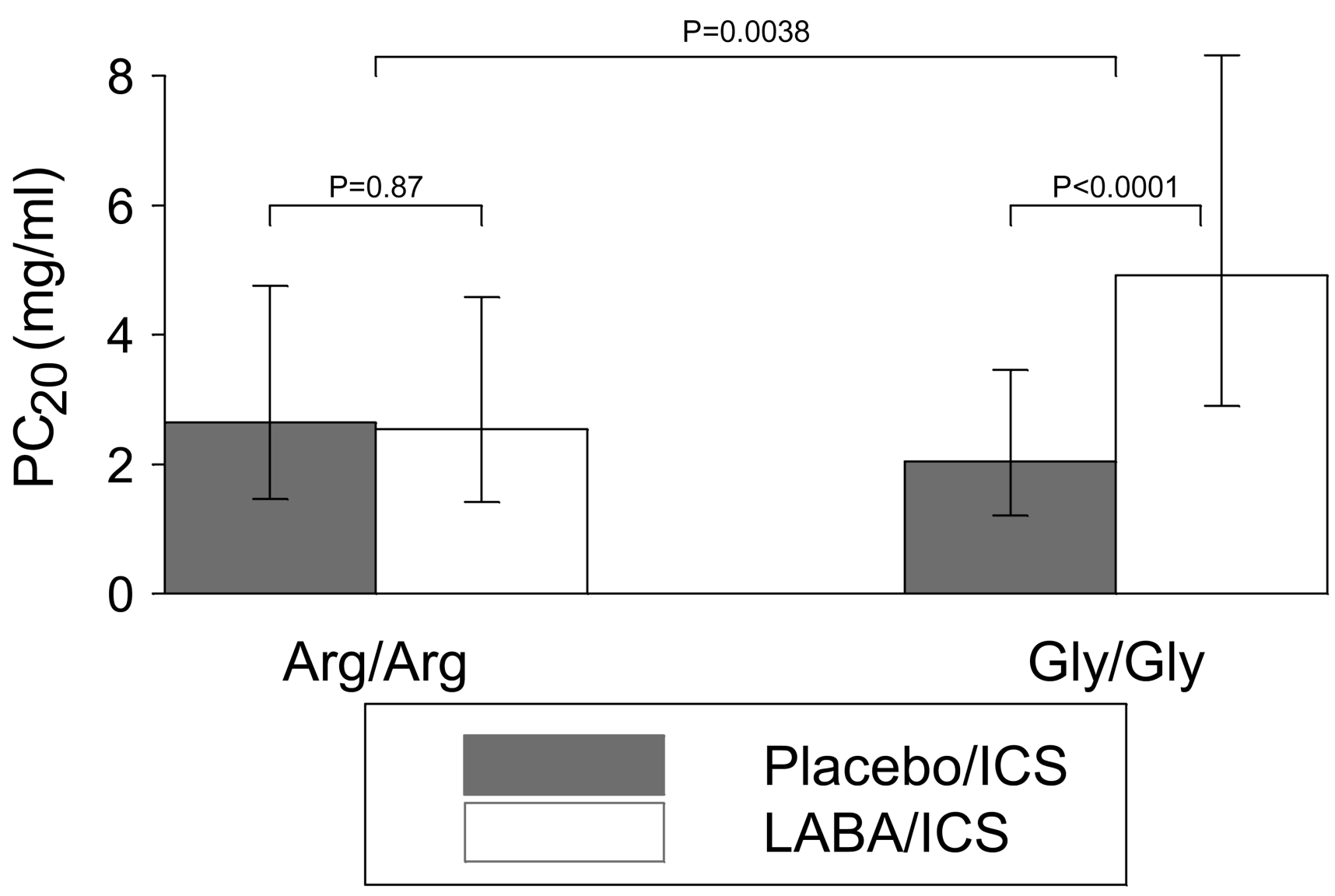




\section{Figure 4b}

\section{Doubling dilution difference in Methacholine $\mathrm{PC}_{20}$}

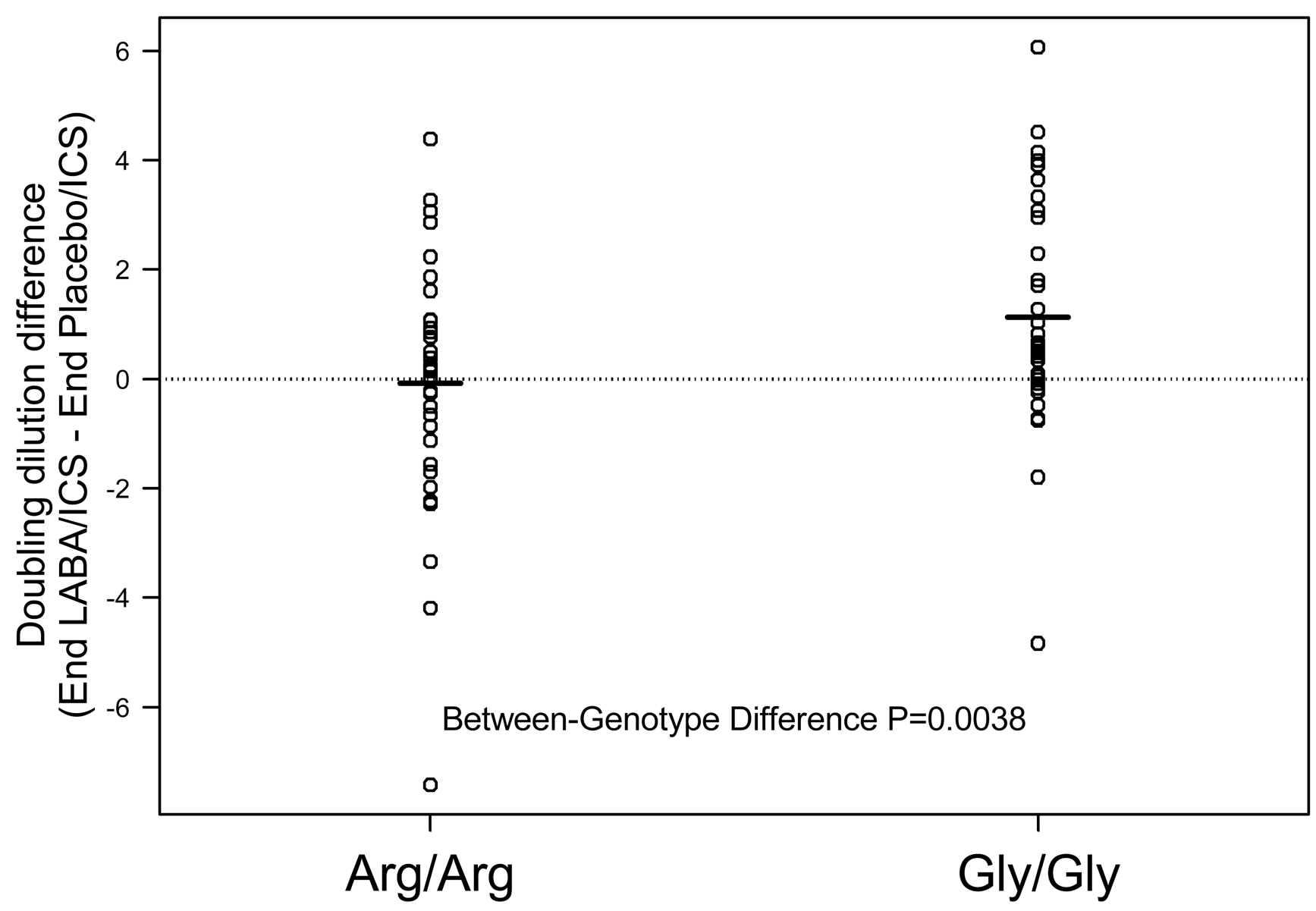

Figure 4.

Figure 4a. Methacholine responsiveness in B16 Arg/Arg subjects and B16 Gly/Gly subjects receiving ICS with placebo or LABA. While B16 Gly/Gly subjects demonstrated a doubling of their methacholine $\mathrm{PC}_{20}$ with salmeterol compared with placebo ( $\left.\mathrm{P}<0.0001\right)$, B16 Arg/ Arg subjects derived no such benefit. This genotype specific difference was significant $(\mathrm{p}=0.0038)$. Data were log transformed for analysis. Bars represent back-transformed $95 \%$ confidence intervals about the geometric mean.

Figure $4 \mathrm{~b}$. Individual raw data for the doubling dilution difference in methacholine $\mathrm{PC}_{20}$, comparing LABA/ICS to Placebo/ICS at the end of each treatment period for B16 Arg/Arg and B16 Gly/Gly subjects. Mean values are depicted as horizontal lines. 71\% of Gly/Gly subjects had an improved $\mathrm{PC}_{20}$ vs. $56 \%$ of Arg/Arg subjects. 


\section{PEF by Genotype in African American Subjects}

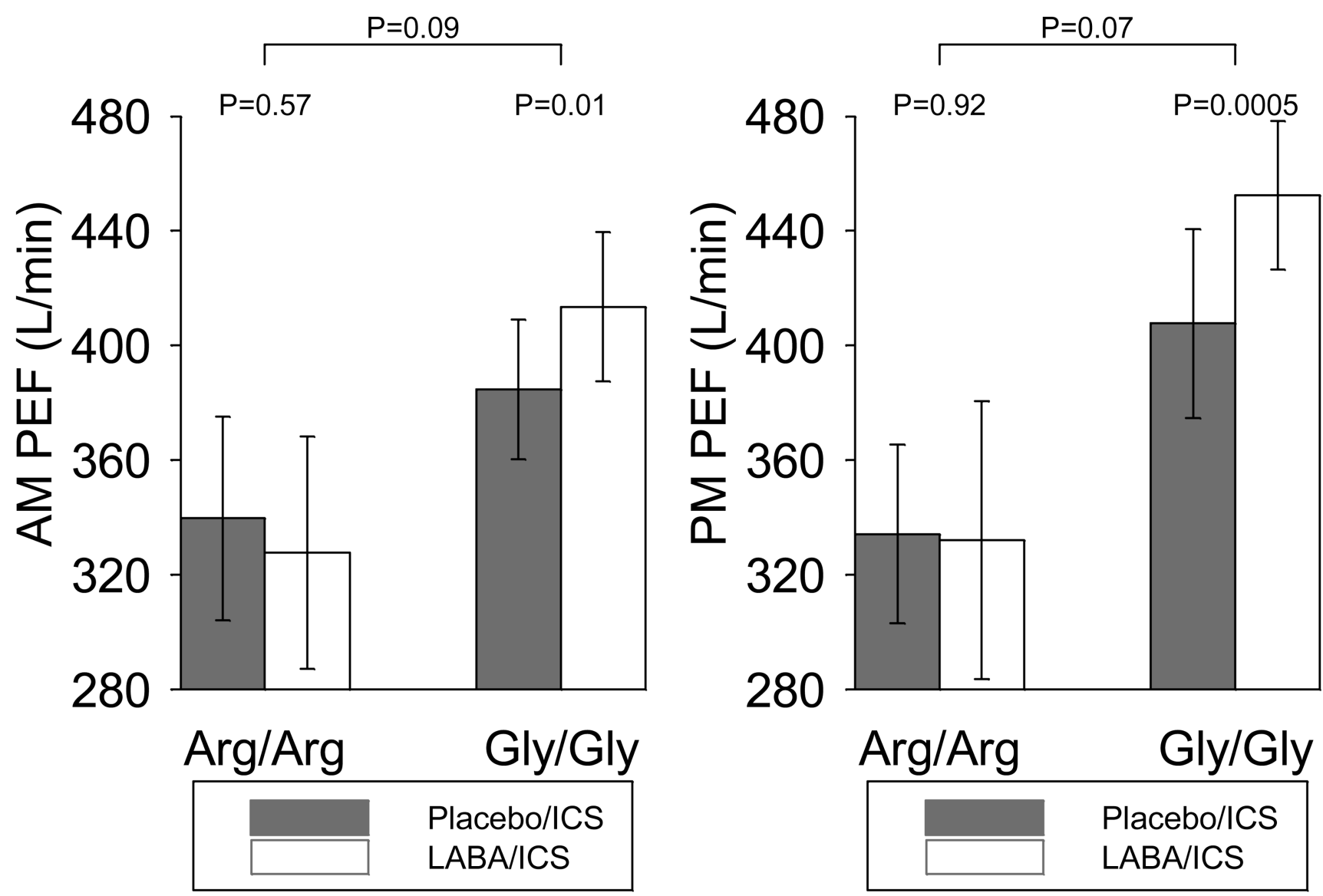

Figure 5.

AM and PM PEF in the 9 African American B16 Arg/Arg and the 8 B16 Gly/Gly subjects receiving ICS with placebo or LABA. African American B16 Gly/Gly subjects ended up with a higher AM PEF with LABA/ICS than with Placebo /ICS; this was not observed with African American B16 Arg/Arg subjects. Bars represent 95\% confidence intervals about the mean. 


\section{TABLE I}

\section{Inclusion And Exclusion Criteria}

A. Screening Inclusion Criteria

1. Male and female subjects, ages 18 and older.

2. Ability to provide informed consent

3. Clinical history consistent with asthma.

4. $\mathrm{FEV}_{1}: \geq 40 \%$ of predicted or $\geq 50 \%$ of predicted for subjects regularly using inhaled corticosteroids

5. If on inhaled steroids, subjects must have been on a stable dose for at least 2 weeks.

6. Genotype eligible: B16-Arg/Arg or B16-Gly/Gly

7. Reversible airway obstruction ( $\geq 12 \%$ and $200 \mathrm{ml}$. improvement in $\mathrm{FEV}_{1}$ after 2 puffs of inhaled albuterol) or bronchial hyperresponsiveness with methacholine $\left(20 \%\right.$ reduction in $\mathrm{FEV}_{1}$ in response to a concentration of inhaled methacholine $\leq 8 \mathrm{mg} / \mathrm{ml}\left(\mathrm{PC}_{20} \leq 8 \mathrm{mg} / \mathrm{ml}\right)$, or $\mathrm{PC}_{20} \leq 16 \mathrm{mg} / \mathrm{ml}$ if on inhaled corticosteroids

8. Non-smoker (total lifetime smoking history < 10 pack-years; no more than five occasions of smoking in the past year; No smoking or use of smokeless tobacco in the prior 30 days.)

\section{B. Exclusion Criteria}

1. Use of greater than the equivalent of $1000 \mu \mathrm{g}$ inhaled fluticasone daily

2. Chronic use of any medication other than beta-agonists or inhaled corticosteroids, except as designated by protocol

3. Lung disease other than asthma

4. Established or suspected diagnosis of vocal cord dysfunction.

5. Significant medical illness (other than asthma) that is not stable.

6. History of respiratory tract infection within the previous 6 weeks

7. History of a significant exacerbation of asthma in the previous 6 weeks

8. History of life-threatening asthma requiring treatment with intubation and mechanical ventilation within the past 10 years.

9. Hyposensitization therapy other than an established maintenance regimen.

10. Pregnancy or lactation. If potentially able to bear children, not using an acceptable form of birth control

11. Subjects who were randomized in the BAGS trial, BARGE trial, SOCS trial, or SLIC trial.

12. History of hypersensitivity to soya lecithin or related food products such as soybeans or peanuts. 
Table 2

Demographics and Baseline Characteristics of Randomized LARGE subjects

\begin{tabular}{|c|c|c|c|}
\hline & $\operatorname{Arg} / \operatorname{Arg}(\mathrm{N}=42)$ & Gly/Gly (N=45) & P-value \\
\hline $\mathrm{AGE}^{*}$ & $39(11)$ & $42(12)$ & $0.21^{T}$ \\
\hline GENDER $^{\wedge}$ : Male & $10(24 \%)$ & $16(36 \%)$ & $0.07^{M}$ \\
\hline $\mathrm{RACE}^{\wedge}:$ Caucasian & $27(64 \%)$ & $31(69 \%)$ & $\dagger$ \\
\hline African American & $9(21 \%)$ & $8(18 \%)$ & \\
\hline Other (Asian/Hispanic) & $6(2 / 4)(14 \%)$ & $6(1 / 5)(13 \%)$ & \\
\hline+ SKIN TEST $^{\wedge}$ & $40(100 \%)^{\ddagger}$ & $40(89 \%)$ & $0.03^{M}$ \\
\hline $\operatorname{AM}$ PEF $(\mathrm{L} / \mathrm{min})^{*}$ & $405(85)$ & 427 (102) & $0.27^{T}$ \\
\hline $\operatorname{PM}$ PEF (L/min) ${ }^{*}$ & $403(87)$ & $430(102)^{\dagger}$ & $0.19^{T}$ \\
\hline $\mathrm{FEV}_{1}(\mathrm{~L}) *$ & $2.56(0.66)$ & $2.66(0.75)$ & $0.58^{T}$ \\
\hline $\mathrm{FEV}_{1} \% *$ & $78.6(13.4)$ & $79.6(15.3)$ & $\dagger$ \\
\hline $\mathrm{FVC}(\mathrm{L}){ }^{*}$ & $3.56(1.03)$ & $3.69(0.95)$ & $0.62^{T}$ \\
\hline $\mathrm{FEV}_{1}$ Albuterol Reversal (4 puffs) $\%$ * & $11.2(6.3)$ & $8.9(6.6)$ & $0.09^{T}$ \\
\hline $\mathrm{FEV}_{1}$ Ipratropium Reversal (4 puffs) $\%$ * & $11.0(7.4)$ & $8.9(5.7)$ & $0.20^{T}$ \\
\hline AM Symptoms * & $0.15(0.26)$ & $0.18(0.22)$ & $0.68^{T}$ \\
\hline Average Daily Puffs Albuterol ${ }^{*}$ & $0.9(1.0)$ & $1.1(1.5)$ & $0.39^{T}$ \\
\hline Methacholine $\mathrm{PC}_{20}(\mathrm{mg} / \mathrm{ml}) * *$ & $2.43(0.57,9.40)$ & $1.92(0.67,3.90)$ & $0.19^{T}$ \\
\hline Exhaled $\mathrm{NO}(\mathrm{ppb}){ }^{+}$ & $16.8(11.7,28.4)$ & $15.8(11.3,24.9)$ & $0.69^{S}$ \\
\hline $\mathrm{EBC}_{\mathrm{pH}}^{+}$ & $8.44(8.35,8.53)$ & $8.44(8.25,8.59)$ & $0.74^{S}$ \\
\hline \# Positive Skin Tests * & $3.7(2.4)$ & $3.7(2.5)$ & $0.51^{T}$ \\
\hline $\operatorname{IgE}^{+}$ & $127(43,308)$ & $152(81,282)$ & $0.93^{S}$ \\
\hline
\end{tabular}

$\mathrm{N}(\%)$ reported

Mean (SD) reported

${ }^{+}$Median $(\mathrm{Q} 1, \mathrm{Q} 3)$ reported

${ }^{* *}$ Geometric mean $(\mathrm{Q} 1, \mathrm{Q} 3)$ reported

$M_{\text {McNemar test }}$

$T$ Paired T-test

$S_{\text {Wilcoxon Signed-Rank test }}$

${ }^{\dagger} \mathrm{P}$-values not shown for matching criteria

* Two subjects did not have skin tests performed 


\begin{tabular}{|c|c|c|c|c|c|c|c|c|c|c|c|c|c|c|c|c|c|}
\hline & 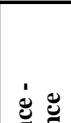 & 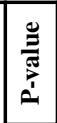 & Oे & $\mid \begin{array}{l}\infty \\
\infty \\
0\end{array}$ & $\bar{m}$ & đ̇. & $\bar{a}$ & $\tilde{\sigma}$ & $\stackrel{m}{0}$ & $\stackrel{\hat{\imath}}{0}$ & 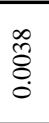 & 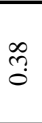 & 苞 & 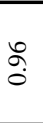 & \&. & oे & 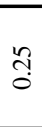 \\
\hline & 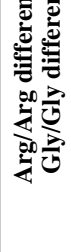 & 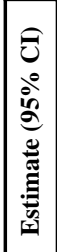 & 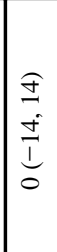 & 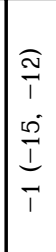 & $\begin{array}{l}\widehat{0} \\
0 \\
0 \\
\dot{1} \\
1 \\
0 \\
0 \\
0 \\
1\end{array}$ & $\begin{array}{l}\widehat{\tilde{o}} \\
0 \\
0 \\
0 \\
0 \\
\underline{1} \\
\tilde{O} \\
0 \\
0 \\
i\end{array}$ & 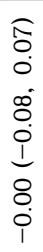 & 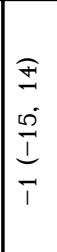 & 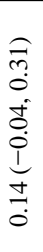 & 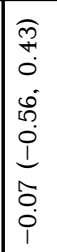 & 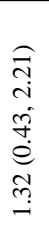 & 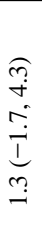 & 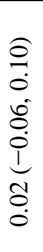 & 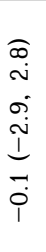 & $\begin{array}{l}\hat{O} \\
0 \\
0 \\
0 \\
0 \\
i \\
0 \\
0 \\
0\end{array}$ & \begin{tabular}{|l}
$\hat{\delta}$ \\
0 \\
0 \\
$\delta$ \\
0 \\
0 \\
$\delta$ \\
0 \\
0
\end{tabular} & $\begin{array}{l}\text { तิ } \\
\vdots \\
0 \\
\dot{0} \\
0 \\
0\end{array}$ \\
\hline & $\underbrace{n}_{i}$ & 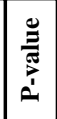 & 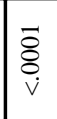 & $\begin{array}{l}\bar{\delta} \\
\dot{8} \\
\dot{v}\end{array}$ & 苟 & 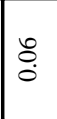 & సે & 命 & $\begin{array}{l}\stackrel{2}{0} \\
\stackrel{0}{0}\end{array}$ & $\mid \begin{array}{l}\infty \\
\infty \\
0\end{array}$ & $\begin{array}{l}\bar{\Xi} \\
\stackrel{\Delta}{v}\end{array}$ & $\begin{array}{l}\text { to } \\
0 \\
0\end{array}$ & ơ & $\stackrel{\infty}{\substack{0 \\
ٍ ్}}$ & oे & 占 & $\stackrel{g}{\circ}$ \\
\hline 苞 & 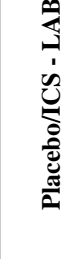 & 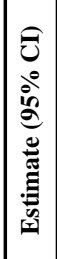 & 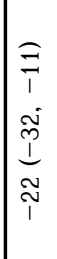 & 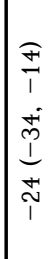 & $\begin{array}{l}\underset{f}{g} \\
\stackrel{0}{0} \\
\dot{0} \\
\stackrel{0}{0}\end{array}$ & $\mid \begin{array}{l}\widehat{O} \\
0 \\
0 \\
0 \\
0 \\
0 \\
1 \\
1 \\
\dot{1} \\
0 \\
0 \\
1\end{array}$ & $\begin{array}{l}\widehat{0} \\
0 \\
0 \\
\dot{o} \\
0 \\
0 \\
1 \\
o \\
0 \\
i \\
i\end{array}$ & 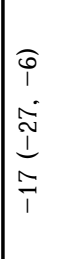 & 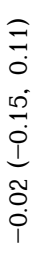 & 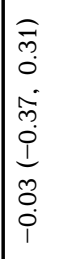 & 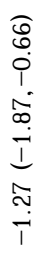 & $\begin{array}{l}\stackrel{f}{+} \\
\dot{+} \\
\vec{i} \\
\overrightarrow{0} \\
\end{array}$ & 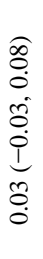 & 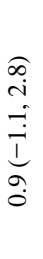 & 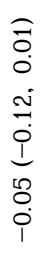 & 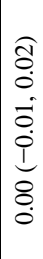 & $\begin{array}{l}\text { तิ } \\
\stackrel{0}{0} \\
\dot{0} \\
\stackrel{0}{0} \\
\dot{0}\end{array}$ \\
\hline & 赵记 & 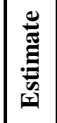 & ঙ̆ & $\underset{z}{\sharp}$ & i & $\begin{array}{l}\underset{i}{\vec{i}} \\
\text { in }\end{array}$ & $\vec{m}$ & 过 & 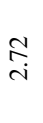 & $\frac{0}{\infty}$ & 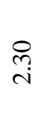 & $\stackrel{n}{n}$ & \&े & $\stackrel{\bullet}{\stackrel{0}{r}}$ & $\begin{array}{l}\stackrel{\partial}{\infty} \\
i \\
i\end{array}$ & 声 & 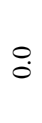 \\
\hline & 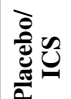 & 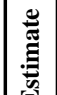 & $\ddot{q}$ & 字 & 0 & $\begin{array}{l}\tilde{b} \\
i\end{array}$ & 5 & ণे & 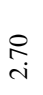 & $\frac{m}{\infty}$ & $\overbrace{\tilde{i}}$ & $\stackrel{9}{ }$ & $\widehat{\Lambda}$ & $\underset{\infty}{+}$ & i. & $\overline{0}$ & $:$ \\
\hline
\end{tabular}


